\title{
KAJIAN DOMAIN KELEMBAGAAN PADA PENGELOLAAN PERIKANAN PELAGIS KECIL DENGAN PENDEKATAN EKOSISTEM DI PERAIRAN ACEH BARAT (STUDI KASUS PPI KUALA BUBON)
}

\section{THE STUDY OF INSTITUTIONAL DOMAIN IN ECOSYSTEM APPROACH TO SMALL PELAGIC FISHERIES MANAGEMENT IN WEST ACEH WATER (CASE STUDY OF KUALA BUBON LANDING FISHERIES PORT)}

\author{
${ }^{1}$ Mohamad Gazali \\ ${ }^{1}$ Prodi Ilmu Kelautan, Fakultas Perikanan dan Ilmu Kelautan, Universitas Teuku Umar \\ Jalan Alue Peunyareng, Meulaboh, Aceh Barat 23615, Aceh ,Telepon (0655) 7003087
}

Korespondensi:mohamadgazali@utu.ac.id

\begin{abstract}
ABSTRAK
Ikan pelagis kecil merupakan salah satu komoditas perikanan Aceh Barat. Namun, tantangan dalam pengelolaan perikanan pelagis kecil masih tumpang tindih antar lembaga pengelolaan perikanan. Tujuan penelitian ini adalah untuk mengkaji domain kelembagaan pada pengelolaan perikanan pelagis kecil dengan pendekatan ekosistem di perairan Aceh Barat (Studi Kasus di PPI Kuala Bubon). Metode penelitian dengan menggunakan penelitian kualitatif. Metode pengumpulan data yaitu metode survey yang dilakukan dengan pendekatan purposive sampling yakni dengan melakukan depth interview terhadap responden yang dianggap informatif dan pengetahuan luas tentang kelembagaan. Analisis data menggunakan analisis EAFM yang dilakukan dengan teknik Flag Modelling. Berdasarkan hasil penelitian bahwa penilaian pada indikator kepatuhan terhadap prinsip-prinsip perikanan yang bertanggung jawab, mekanisme kelembagaan, tingkat sinergitas kebijakan, kelengkapan aturan main. dan kapasitas pemangku kepentingan masih tergolong dalam kondisi sedang. Namun, indikator yang tergolong kondisi buruk yaitu indikator Rencana Pengelolaan Perikanan (RPP). Hal ini menunjukkan bahwa perairan Aceh Barat belum memiliki RPP. Oleh karena itu, perlu adanya dukungan dari pemerintah pusat untuk membantu merumuskan RPP ikan pelagis kecil di Perairan Aceh Barat.
\end{abstract}

Kata kunci : EAFM, Perikanan Pelagis Kecil, domain Kelembagaan.

\begin{abstract}
Small pelagic are one of the commodities of West Aceh Fisheries. However, the challenges of small pelagic fisheries management still yet overlapped between fisheries management institutiona. The aim of this research is to study the institutional domain in ecosystem approach to small pelagic fisheries management. In West Aceh Water (Case study of Landing Fisheries Portof Kuala Bubon). The research method used qualitative approach. The sampling method is survey metohod that undertaken with purpossive sampling approach. Namely dept interview to respondent that regarded informative and wide knowledge regarding institutional. The data analysis used EAFM analysis that undertaken flag modelling technique. According to the result showed the assessment of compliance to responsibility fisheries principals, institutional mechanism, the level of policy sinergity, regulations completionand the capacity of stakeholder indicators were categorized intermediate. Although, fisheries management plan indicator was categorized is bad. It is indicated that the West Aceh water has not yet have fisheries management plan. Therefore, it is necessary to supporting from government for aiding to formulate the small pelagic of fisheries management plan in West Aceh Waters.
\end{abstract}

Keywords : EAFM, Small Pelagic, Institutional domain 
JURNAL TA (O)TI ILMU KELAUTAN

Volume I, Nomor 1, 2019

\section{PENDAHULUAN}

Dalam UUD 1945 Pasal 33 ayat 3 mengamanatkan bahwa bumi dan air dan kekayaan yang terkandung didalamnya dikuasai oleh Negara dan dipergunakan untuk sebesar-besarnya kemakmuran rakyat. Sumberdaya daya ikan pelagis di Perairan Aceh Barat yang strategis berhadapan langsung dengan samudera hindia merupakan suatu kekayaan alam yang terkandun di dalam air, dan oleh sebab itu sudah seharusnya dikuasai oleh Negara dan dipergunakan untuk sebesarbesar kemakmuran rakyat. Sumberdaya ikan tersebut harus didayagunakan untuk mendukung terwujudnya kedaulatan pangan khususnya pasokan protein ikan yang sangat bermanfaat untuk mewujudkan kesejahteraan rakyat.

Pengelolaan perikanan merupakan semua upaya, termasuk proses yang terintegrasi dalam pengumpulan informasi, analisis, perencanaan, konsultasi, pembuatan keputusan, alokasi sumberdaya ikan, dan implementasi serta penegakan hukum dari peraturan-peraturan perundang-undangan dibidang perikanan, yang dilakukan oleh pemerintah atau otoritas lan yang diarahkan untuk mencapai kelangsungan produktivitas sumberdaya hayati perairan dan tujuan yang disepakati (KKP-RI., 2012). Pengelolaan perikanan berkelanjutan dapat dicapai melalui pengelolaan perikanan dengan pendekatan ekosistem (Ecosystem Approach to Fisheries management).

Ecosystem Approach to Fisheries management (EAFM) merupakan sebuah konsep yang menyeimbangkan antara tujuan sosial ekonomi dalam pengelolaan
Available online at:

http://utu.ac.id/index.php/jurnal.html

perikanan (kesejahteraan nelayan, keadilan pemanfaatan sumberdaya ikan) dengan tetap mempertimbangkan pengetahuan, informasi dan ketidakpastian tentang komponen biotik, abiotik, dan interaksi manusia dalam ekosistem perairan melalui sebuah pengelolaan perikanan terpadu, komprehensif dan berkelanjutan (KKP-RI, 2012).

Indonesia sebagai negara kepulauan terbesar yang dikaruniai dengan ekosistem perairan tropis memiliki karakteristik dinamika sumberdaya perairan, termasuk didalamnya, sumberdaya ikan yang tinggi. Tingginya dinamika sumberdaya ikan ini tidak terlepas dari kompleksitas ekosistem tropis (tropical ecosystem complexities), yang telah menjadi salah satu ciri dari ekosistem tropis. Kompleksitas dalam pengelolaan perikanan ini yang mendasari pentingnya penerapan pendekatan ekosistem dalam pengelolaan perikanan (EAFM). Lebih lanjut, pengelolaan perikanan tujuan ultimatnya adalah memberikan manfaat sosial ekonomi yang optimal bagi masyarakat, tidak dapat dilepaskan dari dinamika ekosistem yang menjadi media hidup bagi sumberdaya ikan itu sendiri.

\section{Ecosystem approach Fisheries} Management (EAFM) adalah pendekatan pencapaian tujuan pengelolaan perikanan melalui pemahaman tentang interaksi antara komponen biotik, abiotik dan manusia dalam sebuah unit ekosistem perairan. Lebih lanjut, EAFM melengkapi dan mengintegrasikan berbagai pendekatan yang ada untuk perikanan, kelautan dan pengelolaan sumber daya pesisir (Adrianto et al., 2012) 


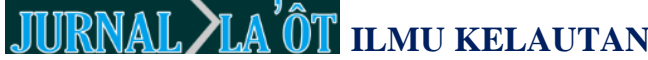

Volume I, Nomor 1, 2019

Upaya pengelolaan perikanan sebagai sebuah unit ekosistem, tentunya kondisi habitat dan ekosistem sangat dibutuhkan. Mengingat dengan terjaganya habitat dan ekosistem akan sangat mempengaruhi terhadap keberlanjutan sumber daya ikan. Berangkat dari hal tersebut, perlu dilakukan penelitian terhadap domain kelembagaan. Lebih lanjut hasil penilaian domain kelembagaan dapat dijadikan sebagai salah satu acuan dalam penentuan kebijakan pengelolaan perikanan berkelanjutan.

Secara alamiah, pengelolaan sistem perikanan tidak dapat dilepaskan dari tiga dimensi yang tidak terpisahkan satu sama lain yaitu (1) dimensi sumberdaya perikanan dan ekosistemnya; (2) dimensi pemanfaatan sumberdaya perikanan untuk kepentingan sosial ekonomi masyarakat; dan (3) dimensi kebijakan perikanan itu sendiri (Charles, 2001). Terkait dengan tiga dimensi tersebut, pengelolaan perikanan saat ini masih belum mempertimbangkan keseimbangan ketiganya, di mana kepentingan pemanfaatan untuk kesejahteraan sosial ekonomi masyarakat dirasakan lebih besar dibanding dengan misalnya kesehatan ekosistemnya. Dengan kata lain, pendekatan yang dilakukan masih parsial belum terintegrasi dalam sebuah batasan ekosistem yang menjadi wadah dari sumberdaya ikan sebagai target pengelolaan. Dalam konteks ini lah, pendekatan terintegrasi melalui pendekatan ekosistem terhadap pengelolaan perikanan Ecosystem Approach to Fisheries Management (EAFM) menjadi sangat penting.
Available online at:

http://utu.ac.id/index.php/jurnal.html

Implementasi EAFM memerlukan perangkat indikator yang dapat digunakan sebagai alat monitoring dan evaluasi mengenai sejauh mana pengelolaan perikanan sudah menerapkan prinsipprinsip pengelolaan berbasis ekosistem. Selanjutnya, dalam konteks manajemen perikanan sebuah indikator dikatakan sebagai sebuah indikator yang baik apabila memenuhi beberapa unsur seperti (1) menggambarkan daya dukung ekosistem; (2) relevan terhadap tujuan dari ko-manajemen; (3) mampu dimengerti oleh seluruh stakeholders; (4) dapat digunakan dalam kerangka monitoring dan evaluasi; (5) long-term view; dan (5) menggambarkan keterkaitan dalam sistem ko-manajemen perikanan. Masing-masing indikator untuk aspek pendekatan ekosistem dalam pengelolaan perikanan meliputi aspek-aspek habitat, sumberdaya ikan, aspek teknis penangkapan ikan, aspek ekonomi, aspek sosial dan aspek kelembagaan.

Kabupaten Aceh Barat merupakan salah satu wilayah operasional pengelolaan perikanan yang masuk kedalam teritorial Wilayah Pengelolaan Perikanan (WPP) 572 dalam operasinya penangkapan kapal ikan yang melanggar tindak Pidana di Perairan Aceh yang terjadi di Perairan Aceh tahun 2011 dan 2013, sesuai dengan data yang diperoleh dari Dinas Kelautan dan Perikanan Aceh. Di kabupaten Aceh Barat tahun 2014 telah menangkap 6 kapal berkapasitas 60-80 GT di perairan Aceh Barat, diduga pelanggaran tanpa dilengkapi dokumen kapal berbendara Malaysia dan Menggunakan alat tangkap Trawl, dengan demikian ini 
JURNAR ]A (0)] ILMU KELAUTAN

Volume I, Nomor 1, 2019

mengindikasikan di wilayah ini ada keterlibatan stakeholder pengelolaan perikanan dengan pendekatan ekosistem diwilayah ini. Selain itu produksi perikanan tangkap ikan cakalang di Kabupaten Aceh Barat pada tahun 2014 mencapai 8.810 ton. (DKP Propinsi Aceh. 2015).

Peran serta kewenangan pemerintah kabupaten Aceh Barat dalam upaya pendekatan pengelolaan sumberdaya perikanan ini mencakup pengelolaan kekayaan alam, baik yang berupa sumberdaya di daratan maupun di lautan. Adapun urusan pengelolaan dalam kelautan yang didesentralisasikan meliputi eksplorasi, konservasi dan pengelolaan kekayaan laut, tata ruang dan administrasi serta penegakan hukum.

Permasalahan yang timbul dalam pengelolaan sumber daya perikanan kelembagaan kurang harmoni antar kelembagaan yang ada. Kurangnya
Available online at:

http://utu.ac.id/index.php/jurnal.html

manajemen dalam pengelolaan sumber daya perikanan khususnya di domain kelembagaan tentang studi Prinsip EAFM, maka perlu di lakukan suatu studi penelitian mengenai pengelolaan sumber daya perikanan pelagis domain kelembagaan dengan pendekatan Ekosistem di Kabupaten Aceh Barat WPPNRI 572. Tujuan Penelitian ini adalah untuk mengkaji domain kelembagaan pada pengelolaan perikanan pelagis kecil dengan pendekatan ekosistem di perairan Aceh Barat.

\section{METODE PENELITIAN \\ Waktu dan Tempat}

Penelitian ini dilaksanakan pada bulan Maret 2019 di TPI Kuala Bubon Kecamatan Samatiga Kabupaten Aceh Barat (Gambar 1).

Pengamatan dalam penelitian ini mengindentifikasi pengelolaan kelembagaan dan menyusun strategi pengelolaan sumber daya perikanan dengan pendekatan ekosistem

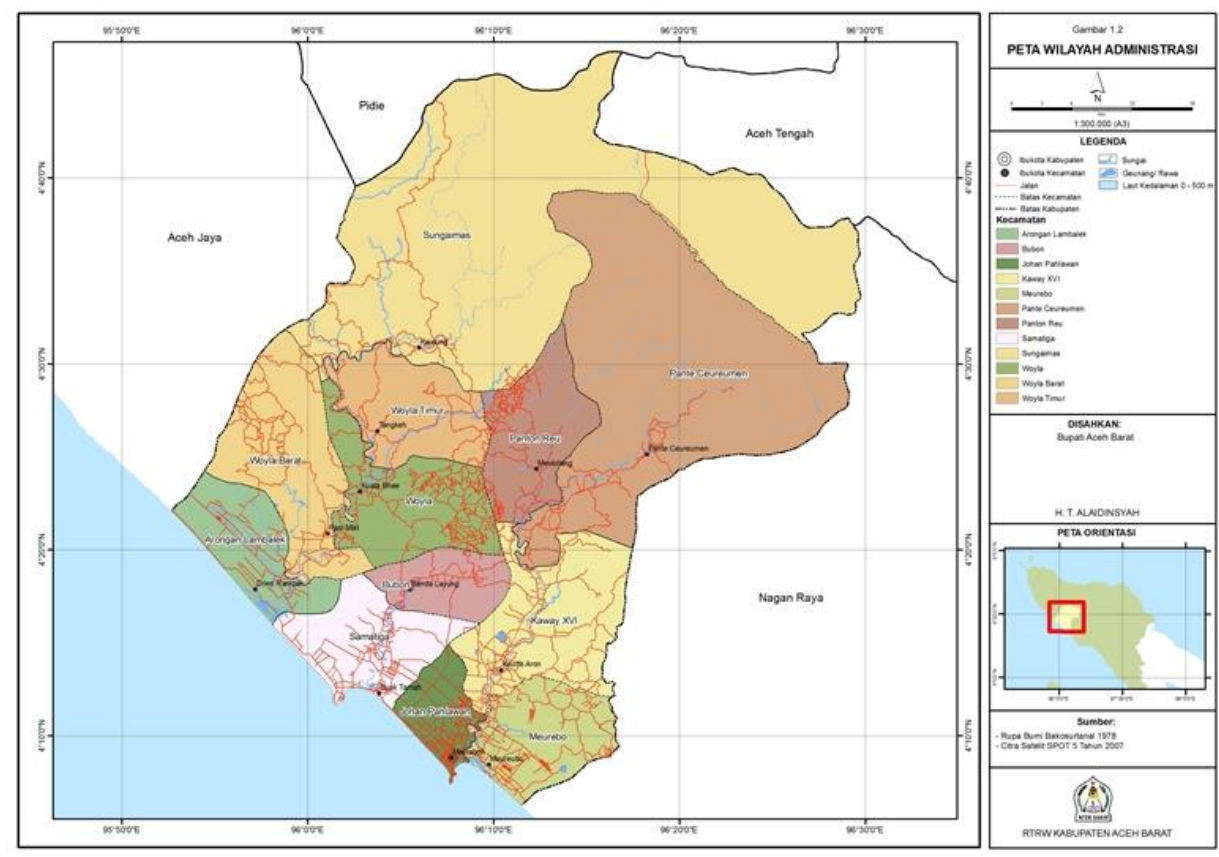

Gambar : Lokasi Penelitian

Sumber : (BPS Aceh Barat, 2015) 
JURNAT \A (O)TI ILMU KELAUTAN

Volume I, Nomor 1, 2019

(EAFM) Domain Kelembagaan pada sumber daya perikanan Pelagis kecil di Kabupaten Aceh Barat WPP-NRI 572.

\section{Metode Pengumpulan Data}

Metode pengambilan data yang digunakan adalah purposive sampling, dimana pengambilan sampel dilakukan secara acak tanpa memperhatikan strata yang ada dalam populasi. Sampel diambil secara purposive dengan tujuan mendapatkan gambaran kondisi pengelolaan sumberdaya perikanan karangberbasis EAFM di kelembagaan Kabupaten Aceh Jaya. Pemilihan responden berdasarkan pertimbangan banyaknya informasi yang diketahui atau dikuasai responden.Data yang dikumpulkan mencakup data primer dan data sekunder.

Data primer untuk wawancara dan kuisioner diproleh dari sampel responden yang dipilih secara khusus dari pelaku (individu atau organisasi) yang mengerti terhadap permasalahan penelitian. Pengisian kuisioner dan wawancara ditujukan langsung kepada pihak POKMASWAS, Panglima Laot, Dinas Kelautan dan Perikanan, LSM dan Nelayan. Sementara itu, data sekunder dikumpulkan mengenai informasi tentang pengelolaan sumberdaya perikanan karang berupa laporan data statistik perikanan, laporan rencana pengelolaan wilayah pesisir dan literatur yang terkait

\section{Analisis Data}

Analisis EAFM merupakan salah satu pendekatan multi atribut dengan pendekatan kepada gejala atau performa indikasi kondisi ekosistem perairan secara umum (KKP, 2012). Menurut FAO (2005), terdapat
Available online at:

http://utu.ac.id/index.php/jurnal.html

beberapa prinsip yang harus diperhatikan dalam implementasi pengelolaan perikanan dengan pendekatan ekosistem (EAFM) yaitu; (1) Perikanan harus dikelola pada batas yang memberikan dampak yang dapat ditoleransi oleh ekosistem; (2) Interaksi ekologis antar sumberdaya ikan dan ekosistemnya harus dijaga; (3) Perangkat pengelolaan sebaiknya compatible untuk semua distribusi sumberdaya ikan; (4) Tindakan pencegahan dalam pengambilan keputusan diperlukan karena pengetahuan terhadap ekosistem tidak lengkap/terbatas; (5) Tata kelola perikanan mencakup kepentingan sistem ekologi dan sistem manusia.

Analisis EAFM ini dilakukan melalui pendekatan indikator. Indikator secara sederhana didefinisikan sebagai sebagai sebuah alat atau jalan untuk mengukur, mengindikasikan, atau merujuk sesuatu hal dengan lebih atau kurang dari ukuran yang diinginkan (Gavaris, 2009). Pada penelitian ini dilakukan penilaian terhadap 26 indikator yang terbagi kedalam enam domain. Setiap indikator memiliki kriteria dan bobot penilaian yang berbeda (KKP, 2012).

Dari proses pemberian skor tersebut, pada tahap awal kita bisa mengetahui kelompok-kelompok parameter mana yang tergolong terendah (berada dalam reference point rendah) dan mana yang dalam reference point tinggi. Parameter terendah dengan warna merah, sedang warna kuning dan parameter tinggi warna hijau.

Tentukan bobot berdasarkan rangking (brij) untuk setiap indikator ke-i, domain ke-j 
JURNAR ]A (0)] ILMU KELAUTAN

Volume I, Nomor 1, 2019

Menetapkan bobot dari setiap atribut, setiap atribut memiliki nilai kepentingan yang berbeda-beda. Perbedaan parameter kepentingan ini dilihat setelah menetapkan semua atribut dalam domain. Kenudian ditetapkan bobot setiap atribut sesuai dengan derajat pengaruuh atribut tersebut dalam domain. Pembobotan ditetapkan dalam skala 0-100. Atribut yang nemiliki bobot besar dianggap memeiliki nilai kepentingan tinggi dalam domain tersebut. Bobt yang memiliki bobot rendah memeiliki kepentingan yang rendah dalam domain tersebut. Pembobotan maksimal tiao domain 100 yang dibagi habis dalam setiap atribut.

Identifikasi tingkat konektivitas (densitas) antar domain dan indikator dengan menentukan skor domain (sdi) dari hasil coginitive mapping keterkaitan indikator. Kerkaitan ini merupakan salah satu penciri utama dari EAFM.

Penentuan densitas (konektivitas) dalam setiap atribut. Densitas setiap atribut berbeda ditetapkan dalam skala nilai yang berbeda. Densitas setiap atribut yaitu tingkat keterkaitan sebuah atribut dengan atribut lainnya. Keterkaitan dilihat dari semua atribut EAFM, kemudian dilihat tingkat ketertarikannya (langsung atau tidak). Densitas maksimal mungkin terjadi apabila atribut memiliki hubungan dengan atribut lain selain dirinya. Sehingga densitas maksimum akan
Available online at:

http://utu.ac.id/index.php/jurnal.html

berjumlah (n-1), dimana $\mathrm{n}$ adalah total dari atribut EAFM yang dikaji.

Selain skor atribut bagian yang penting perlu diperhatikan pengaruhnya adalah nilai densitas. Nilai densitas didefinisikan sebagai jumlah ketertarikan dari setiap atribut terhadap atribut lainnya. Sehingga itu menunjukkan besaran pengaruh dari suatu atribut terhadap atribut lainnya. Secara umum keseluruhan atribut memberikan peluang memiliki hubungan dengan atribut lainnya kecuali dirinya sendiri. Dalam kontek ini pemberian nilai densitas juga akan menunjukkan pengaruhnya terhadap perhitungan secara keseluruhan. Logika sederhananya adalah setiap atribut yang memiliki keterkaitan tinggi (banyak) terhadap atribut lainnya, akan tergolong sebagai atribut yang memiliki peran besar dalam ekosistem suatu kawasan. Agar kita dapat melakukan evaluasi nilai densitas, maka densitas akan dikelompokkan dalam beberapa batasan nilai sebagai berikut: 
JURNAL DA (0)TI ILMU KELAUTAN

Volume I, Nomor 1, 2019
Available online at:

http://utu.ac.id/index.php/jurnal.html

Tabel 4. Visualisasi Model Bendera

\begin{tabular}{|c|c|c|c|}
\hline \multicolumn{2}{|c|}{ Kriteria Komposit } & \multirow{2}{*}{ Deskripsi } & Warna \\
\hline Batas Bawah & Batas Atas & & \\
\hline 1 & 20 & Buruk & \\
\hline 21 & 40 & Kurang & \\
\hline 41 & 60 & Sedang & \\
\hline 61 & 80 & Baik & \\
\hline 81 & 100 & Baik Sekali & \\
\hline & & & \\
\hline
\end{tabular}

Sumber: (Kementerian Kelautan dan Perikanan Republik Indonesia , 2012)

Kembangkan penilaian komposit pada masing-masing domain ke-j (Dj) dengan formula sederhana sebagai berikut :

$\mathrm{C}_{\mathrm{at}}{ }^{-}{ }=\mathrm{S}_{a i} \times \mathrm{W}_{i} \times \mathrm{D}_{i}$

Dimana:

$\mathrm{C}_{\mathrm{at}^{-} i}=$ Nilai total EAFM dari satu atribut dalam domain

$\mathrm{S}_{a i} \quad=$ Skor atribut ke-i

$\mathrm{W}_{i} \quad=$ Bobot atribut ke-i

$\mathrm{D}_{i} \quad=$ Densitas atribut $\mathrm{ke}=\mathrm{i}$

Evaluasi atribut EAFM di suatu lokasi ditetapkan berdasarkan hasil evaluasi dari indikator yang ditetapkan di semua lokasi sampling. Evaluasi yang dilakukan dengan menetapkan batasan dan kriteria EAFM dari berdasarkan reference point yang ada.

$\checkmark$ Kembangkan indeks komposit agregat untuk seluruh domain ke-j (Dj) pada unit perikanan yang dievaluasi (misalnya WPP) dengan model fungsi sebagai berikut
$: C-w P P i=f\left(D_{j}, n s_{i j}, b r_{i j}, s d_{i}\right)$. Basis formula untuk analisis komposit agregat adalah :

C-wPPi $=A V E d_{j}: n s_{i j} \times b_{i j} \times s_{i}$

Dimana : $\mathrm{AVE}=$ rata-rata aritmetik dari domain ke-j (Dj) dari total perkalian antara nsij (nilai skor indikator ke-i dari domain ke-j) dan brij (bobot ranking indikator ke-i domain ke-j) dan sdi (skor densitas dari indikator ke-i). atau secara sederhana juga dituliskan sebagai berikut:

$\sum C_{a t-i}=S_{\mathrm{ai}} \times W_{i} \times D_{i}$

Dimana:

$\sum C_{a t-i}=$ Total nilai dari dari domain ke-i

$S_{\mathrm{ai}} \quad=$ Skor atribut ke-i

$W_{i} \quad=$ Bobot atribut ke-i

$D_{i} \quad=$ Densitas atribut ke-i

Dari total tiap indikator yang dinilai, kemudian dianalisis dengan 
JURNAT \A (O)TI ILMU KELAUTAN

Volume I, Nomor 1, 2019

menggunakan analisis komposit sederhana berbasis rataan aritmatik yang kemudian ditampilkan dalambentuk model bendera (flag model) dengan kriteria. Indeks komposit ini merupakan nilai konversi nilai total setiap domain EAFM. Proses konversi ini diperlukan agar diperoleh batasan yang baku dari nilai EAFM. Nilai total dari perkalian komponen EAFM selanjutnya di konversi dalam skala 1-100. Konversi ini di perlukan untuk memudahkan pengkiasan atau pengkategorian suatu domain EAFM. Nilai konversi skala setiap domain adalah:

$$
N K-i=\frac{c_{a t-i}}{c_{a t-i \max }} X 100
$$

$C_{a t-i}=$ Nilai total EAFM dari satu atribut dalam domain

$C_{a t-i m a x}=$ Nilai maksimum dari satu atribut dalam domain yang diperoleh saat semua atribut memiliki skor 3.

Cat-imax akan bernilai maksimum apabila semuaskor atribut dalam suatu domain bernilai 3. Artinya semua atribut berada dalam reference point tertinggi atau disebut juga dalam kategori baik.

Metode-metode yang digunakan dalam penelitian ini dapat diuraikan sebagai berikut:
Available online at:

http://utu.ac.id/index.php/jurnal.html

1. Pengamatan Partisipatif

Metode ini dilakukan dengan cara mengamati secara langsung tentang kondisi di lapangan, baik yang berupa keadaan fisik maupun perilaku yang terjadi selama berlangsungnya penelitian. Dalam pengertian sempit observasi berarti pengamatan dan pencatatan secara sistematis terhadap fenomena yang diselidiki.

2. Wawancara Mendalam

Wawancara merupakan salah satu teknik pengumpulan data untuk mendapatkan informasi dengan cara bertanya langsung kepada responden.

3. Analisis Dokumen

\section{HASIL DAN PEMBAHASAN}

Domain Kelembagaan

Penilaian indikator pada domain kelembagaan dilakukan terhadap enam indikator (Tabel 1). Hasil analisis komposit menunjukkan bahwa nilai komposit. Domain kelembagaan yaitu sebesar 48,84. Pada domain kelembagaan hanya terdapat satu indikator yang tergolong dalam kondisi buruk yaitu wilayah Perairan Aceh Barat masih belum memiliki Rencana Pengelolaan Perikanan (RPP) terkait dengan pengelolaan perikanan pelagis kecil. RPP merupakan pedoman dan acuan dengan mempertimbangkan aspek ekologi, ekonomi, sosial dalam merencanakan, memanfaatkan dan mengawasi kegiatan perikanan. RPP dapat dibangun berbasis kawasan perairan (Perairan pesisir, perairan umum) atau berbasis komoditas perikanan. Analisis komposit domain kelembagaan dapat disajikan pada Tabel 1. 


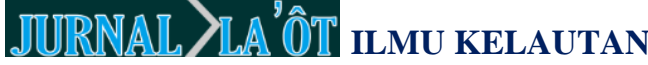

Volume I, Nomor 1, 2019
Available online at:

http://utu.ac.id/index.php/jurnal.html

Tabel 1. Analisis Komposit Domain Kelembagaan

\begin{tabular}{|c|c|c|c|c|c|c|c|c|c|}
\hline Kelembagaan & $1 *$ & $2 *$ & $3 *$ & $4 *$ & $5^{*}$ & $6^{*}$ & Total & Nilai & Ket \\
\hline Hasil & $\begin{array}{c}<2 \text { kali } \\
\text { Pelangga } \\
\text { ran }\end{array}$ & $\begin{array}{c}\text { tetap } \\
\text { dan } \\
\text { tidak } \\
\text { Bertam } \\
\text { bah } \\
\text { Aturan }\end{array}$ & $\begin{array}{l}\text { Tidak } \\
\text { sepenu } \\
\text { hnya } \\
\text { dijalan } \\
\text { kan }\end{array}$ & $\begin{array}{l}\text { Belum } \\
\text { ada } \\
\text { RPP }\end{array}$ & $\begin{array}{c}\text { Ada } \\
\text { Komunikasi } \\
\text { namun } \\
\text { belum } \\
\text { efektif antar } \\
\text { lembaga }\end{array}$ & $\begin{array}{c}\text { Ada } \\
\text { namun } \\
\text { belum } \\
\text { berfungsi } \\
\text { sesuai } \\
\text { pekerjaan }\end{array}$ & & & \multirow[b]{5}{*}{ Sedang } \\
\hline Skor & 2,1 & 2,0 & 2,1 & 1,1 & 2,0 & 2,0 & & & \\
\hline Bobot & 25 & 22 & 18 & 15 & 11 & 9 & & & \\
\hline Skor Densitas & 29 & 28 & 12 & 28 & 18 & 29 & & & \\
\hline Nilai & 1523 & 1355 & 454 & 1 & 396 & 522 & 4250 & 48,84 & \\
\hline
\end{tabular}

Ket : *1) Kepatuhan terhadap prinsip-perinsip perikanan yang bertanggung jawab, 2) kelengkapan aturan main, 3) mekanisme kelembagaan, 4) rencana pengelolaan perikanan, 5) tingkat sinergitas kebijakan dan kelembagaan pengelolaan perikanan, 6) kapasitas pemangku kepentingan

Sumber : (Data primer diolah, 2019)

Indikator yang tergolong dalam kondisi sedang ada lima indikator meliputi indikator pertama yaitu kepatuhan terhadap prinsipprinsip perikanan yang bertanggung jawab dalam pengelolaan perikanan yang telah ditetapkan baik secara formal maupun non formal. Frekuensi pelanggaran yang terjadi berkisar 2-4 kali per tahun. Pelanggaran meliputi penggunaan alat tangkap tidak ramah lingkungan dan belum memiliki SIUP dan SKKck. Kelembagaan senantiasa berbarengan dengan kebijakan. Kebijakan yang bagus tanpa didukung kelembagaan yang baik akan membawa proses pembangunan ke arah yang baik. Pengalaman menunjukkan bahwa kegagalan pembangunan bersumber dari kegagalan pemerintah dalam menerapkan kebijakan serta mengabaikan pembangunan kelembagaan yang seharusnya menjadi dasar dari seluruh proses pembangunan baik ekonomi, sosial, politik maupun pengelolaan sumberdaya alam.
Indikator kedua yaitu kelengkapan aturan main kelengkapan aturan main. Kelengkapan aturan main dalam pengelolaan perikanan pelagis kecil tetap dan tidak bertambah. Kelengkapan aturan main dalam pengelolaan merupakan tingkat ketersediaan regulasi (peraturan), peralatan, petugas dan insfrastruktur pengelolaan perikanan lainnya. Ada tidaknya penegakan aturan main serta efektivitas dalam pengelolaan perikanan. Peraturan yang lengkap menjadi dasar dalam pelaksanaan pengelolaan perikanan yang bertanggungjawab. Kelengkapan peraturan secara otomatis dapat terimplementasi dengan baik. Oleh karena itu, dibutuhkan adanya penegakan aturan tersebut. Ketersediaan aturan saja tidak cukup dan menjamin terlaksananya aturan dengan baik. Tetapi diikuti dengan penegakan hukum yang nyata sehingga aturan yang dibuat bersifat fungsional. 
JURNAL TA (O)TI ILMU KELAUTAN

Volume I, Nomor 1, 2019

Indikator ketiga yaitu mekanisme pengambilan keputusan dimana belum sepenuhnya dijalankan. Mekanisme kelembagaan terkait dengan prosedur/norma/aturan main yang dibangun khususnya dalam pengelolaan perikanan. Mekanisme kelembagaan juga diartikan sebagai metode /teknik organisasi sosial dalam pengelolaan perikanan. Terdapat prosedur dan tata cara yang jelas dalam membangun aturan main. Prosedur dan tata cara tersebut idealnya sudah terbangun menjadi sebuah sistem dan tata nilai yang terimplementasi dalam aspek pengelolaan perikananda dikawal dengan sanksi bagi yang melanggarnya. Mekanisme kelembagaan merupakan hasil negosiasi antara berbagai pihak/pemangku kepentingan dalam pengelolaan perikanan.

Indikator yang kelima adalah sinergitas kebijakan dan kelembagaan pengelolaan perikanan. Hasil penelitian menunjukkan bahwa setiap lembaga pengelolaan perikanan sudah melakukan komunikasi namun belum efektif dijalankan pada masing-masing lembaga. Tingkat sinergitas antar kebijakan dan lembaga dalam pengelolaan perikanan dapat diartikan sebagai adanya keterpaduan gerak dan langkah antar lembaga dan antar kebijakan dalam pengelolaan perikanan sehingga tidak terjadi konflik kepentingan dan benturan kebijakan. Keberhasilan pengelolaan perikanan ditentukan sejauhmana terjadi sinergitas antara lembaga pengelola perikanan. Setiap lembaga selalu terkait dengan kebijakan terkait.

Indikator keenam yaitu kapasitas pemangku kepentingan. Berdasarkan hasil penelitian bahwa pemangku kepentingan memiliki kapasitas akan tetapi belum berfungsi sesuai pekerjaan. Pengelolaan perikanan ditentukan oleh seberapa jauh
Available online at:

http://utu.ac.id/index.php/jurnal.html

kapasitas pemangku kepentingan dalam mengelola perikanan. Ketersediaan peraturan tidak menjamin dapat ditafsirkan dengan baik tanpa didukung oleh kapasitas pemangku kepentingan yang memadai. Kapasitas pemangku kepentingan menentukan baik buruknya kebijakan yang akan dipilih dalam pengelolaan perikanan. Kapasitas pemangku kepentingan juga terlibat dalam menafsirkan perundangan yang berlaku terkait dengan pengelolaan perikanan. Oleh karena itu, semakin tinggi tingkat kompetensi pemangku kepentingan maka efektivitas pengelolaan akan terjamin. Pemangku kepentingan dalam pengelolaan perikanan berupa instansi pemerintah, lembaga/organisasi masyarakat dan perorangan. Kapasitas pemangku kepentingan menentukan pengelolaan perikanan mulai dari aspek perencanaan, pemanfaatan dan pengawasan.

\section{Keputusan Taktis (Tactical Decision)}

Perencanaan pengelolaan perikanan dengan pendekatan ekosistem dapat dilakukan dengan menerjemahkan tujuan pengelolaan ke dalam strategi dan menentukan langkahlangkah taktis untuk mencapai strategi. Gavaris (2009), menyatakan bahwa terdapat dua jenis keputusan bagi manajemen yaitu, strategic decisions (membangun referensi yang cocok untuk tekanan) dan tactical decisions (mengidentifikasi tingkat dari ukuran manajemen yang menjaga tekanan relatif yang dapat diterima terhadap referensi). Pendekatan keputusan taktis (tactical decision) merupakan suatu tindakan untuk menentukan langkah taktis akan dilakukan untuk mencapai strategi pengelolaan 
JURNAL DA (O)TI ILMU KELAUTAN

Volume I, Nomor 1, 2019
Available online at:

http://utu.ac.id/index.php/jurnal.html

Tabel 2. Langkah taktis domain kelembagaan

\begin{tabular}{|c|c|c|c|c|c|c|}
\hline \multirow[t]{2}{*}{ Atribut } & & \multicolumn{3}{|c|}{ Nilai Aktual } & \multirow{2}{*}{\multicolumn{2}{|c|}{$\begin{array}{l}\text { Referensi } \\
\text { indikator } \\
\text { Kriteria } \\
\end{array}$}} \\
\hline & & skor & Kriteria & Skor & & \\
\hline & $\begin{array}{l}\text { Kepatuhan } \\
\text { terhadap prinsip- } \\
\text { perinsip } \\
\text { perikanan yang } \\
\text { bertanggung } \\
\text { jawab }\end{array}$ & 2 & $\begin{array}{l}\text { Frekuensi } \\
\text { pelanggaran } \\
\text { antara 2- } \\
4 \quad \text { kasus } \\
\text { dalam satu } \\
\text { tahun }\end{array}$ & 3 & $\begin{array}{l}\text { Frek } \\
\text { pelanggaran < } \\
2 \text { kasus }\end{array}$ & $\begin{array}{l}\text { Pengawasan dan } \\
\text { penegakan hukum } \\
\text { bagi nelayan yang } \\
\text { menggunakan alat } \\
\text { tangkap tidak ramah } \\
\text { lingkungan }\end{array}$ \\
\hline 2. & $\begin{array}{l}\text { Kelengkapan } \\
\text { aturan main }\end{array}$ & 2 & $\begin{array}{l}\text { Ada tapi } \\
\text { jumlahnya } \\
\text { tetap }\end{array}$ & 3 & $\begin{array}{l}\text { Ada dan } \\
\text { jumlahnya } \\
\text { bertambah }\end{array}$ & $\begin{array}{l}\text { Menambah aturan } \\
\text { penegakan hukum } \\
\text { terhadap pelanggaran } \\
\text { Pengelolaan } \\
\text { perikanan }\end{array}$ \\
\hline 3. & $\begin{array}{l}\text { Mekanisme } \\
\text { kelembagaan }\end{array}$ & 2 & $\begin{array}{l}\text { Apabila } \\
\text { keputusan } \\
\text { dikeluarkan } \\
\text { tetapi tidak } \\
\text { dijalankan } \\
\text { sepenuhnya }\end{array}$ & 3 & $\begin{array}{l}\text { Apabila } \\
\text { keputusan } \\
\text { dikeluarkan dan } \\
\text { dijalankan } \\
\text { sepenuhnya }\end{array}$ & $\begin{array}{l}\text { Monitoring dan } \\
\text { pengawasan } \\
\text { terhadap pelanggaran }\end{array}$ \\
\hline 4. & $\begin{array}{l}\text { Rencana } \\
\text { pengelolaan } \\
\text { perikanan (RPP) }\end{array}$ & 1 & $\begin{array}{l}\text { Belum terdapat } \\
\text { RPP }\end{array}$ & 2 & $\begin{array}{l}\text { Ada RPP } \\
\text { namun belum } \\
\text { dijalankan } \\
\text { sepenuhnya }\end{array}$ & $\begin{array}{l}\text { Melakukan } \\
\text { monitoring rencana } \\
\text { pengelolaan } \\
\text { perikanan (RPP) }\end{array}$ \\
\hline 5. & $\begin{array}{l}\text { Tingkat sinergitas } \\
\text { kebijakan dan } \\
\text { kelembagaan } \\
\text { pengelolaan } \\
\text { perikanan, }\end{array}$ & 2 & $\begin{array}{l}\text { Terdapat } \\
\text { komunikasi } \\
\text { tetapi belum } \\
\text { efektif }\end{array}$ & 3 & $\begin{array}{l}\text { Sinergi anta } \\
\text { lembaga berjalar } \\
\text { baik }\end{array}$ & $\begin{array}{l}\text { rMeningkatkan } \\
\text { akomunikasi } \\
\text { kerjasama } \\
\text { stakeholder }\end{array}$ \\
\hline 6. & $\begin{array}{l}\text { Kapasitas } \\
\text { pemangku } \\
\text { kepentingan }\end{array}$ & 2 & $\begin{array}{l}\text { Ada upaya } \\
\text { namun tidak } \\
\text { difungsikan }\end{array}$ & 3 & $\begin{array}{l}\text { Ada upaya dar } \\
\text { difungsikan } \\
\text { dengan baik }\end{array}$ & $\begin{array}{l}\text { Meningkatkan } \\
\text { kapasitas pemangku } \\
\text { kepentingan yang } \\
\text { difungsikan pada } \\
\text { pengelolaannya }\end{array}$ \\
\hline
\end{tabular}

Sumber : (Data Primer diolah kembali, 2019) 
JURNAT \A (O)T ILMU KELAUTAN

Volume I, Nomor 1, 2019

yang telah ditetapkan. Pengambilan keputusan taktis adalah memutuskan pada tindakan (taktik) untuk mencapai strategi pengelolaan (Trophia Ltd, 2011).

Langkah taktis dalam pengelolaan perikanan dengan pendekatan ekosistem dilakukan terhadap 6 indikator domain kelembagaan. Langkah taktis ini perlu dilakukan agar dilakukan agar dapat meningkatkan status perairan Aceh Barat dari status sedang menjadi baik.

\section{KESIMPULAN DAN SARAN \\ Kesimpulan}

Penilaian perikanan melalui indikator domain kelembagaan EAFM didapatkan bahwa status atau kondisi perikanan pelagis kecil di perairan Aceh Barat (studi kasus PPI Kuala Bubon) termasuk dalam kategori sedang. Strategi perikanan di perairan Aceh Barat dirumuskan terhadap semua indikator berdasarkan nilai reference point tiap indikator. Langkah taktis dirumuskan pada indikator yang memiliki penilaian sedang dan kurang baik. Rumusan langkah taktis tersebut yaitu pengawasan dan penegakan hukum bagi nelayan yang menggunakan alat tangkap tidak ramah lingkungan, Pengawasan dan penegakan hukum bagi nelayan yang menggunakan alat tangkap tidak ramah lingkungan, monitoring dan pengawasan terhadap pelanggaran, melakukan monitoring rencana pengelolaan perikanan (RPP), Meningkatkan komunikasi dan kerjasama antar stakeholder, dan meningkatkan kapasitas pemangku kepentingan yang difungsikan pada pengelolaannya.
Available online at:

http://utu.ac.id/index.php/jurnal.html

\section{Saran}

Kajian tentang domain EAFM lainnya meliputi domain habitat, SDI, teknologi penangkapan, sosial dan ekonomi perlu dilakukan agar memperoleh data aggregat/komposit seluruh domain EAFM.

\section{UCAPAN TERIMA KASIH}

Ucapan terima kasih yang setinggitingginya kepada mahasiswa Fakultas Perikanan dan Ilmu Kelautan Universitas Teuku Umar yang membantu dalam pelaksanaan pengambilan sampel di lapangan PPI Kuala Bubon.

\section{DAFTAR PUSTAKA}

Adrianto, L, Abdullah H, Achmad F, Audillah A, Handoko AS Imam M, Mukhlis K, Sugeng HW, dan Yusli W., 2012. Modul Penelitian Pendekatan Ekosistem dalam Pengelolaan Perikanan (EAFM). Jakarta: Direktorat Sumberdaya Ikan, WWF-Indonesia, dan Pusat Kajian Sumberdaya Pesisir dan Lautan IPB.

Badan Pusat Statistik, 2013. Aceh Barat Dalam Angka

Dinas Kelautan dan Perikanan, 2015. Statistik Produksi Perikanan Cakalang, Kabupaten Aceh Barat.

[FAO] Food and Agriculture Organization of The United Nations. 2005. Putting Into Practice The Ecosystem Approach to Fisheries. Rome

Gavaris S. 2009. Fisheries management planning and support for strategic and tactical decisions in an ecosystem approach context. Fisheries Research. 100: 6-14 


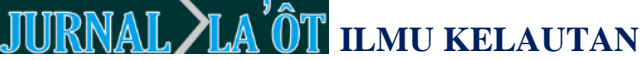

Volume I, Nomor 1, 2019
Available online at:

http://utu.ac.id/index.php/jurnal.html

[KKP] Kementrian Kelautan dan Perikanan, [WWF-Indonesia] World Wide Foundation, [PKSPL-IPB] Pusat Kajian Sumberdaya Laut dan Pesisir, Institut Pertanian Bogor. 2012. Penilaian Indikator Pendekatan Ekosistem Untuk Pengelolaan Perikanan (Ecosystem Approach to Fisheries Management). Modul Training.

Trophia Ltd. 2011. Fisheries management procedures: a potential decision making tool for fisheries management in California. Quantitative Resource Assessment LLC. California 